\title{
The anatomical relationship between recurrent laryngeal nerve and high inferior thyroid artery: a case report
}

\author{
Kemal Emre Özen (D), Kübra Erdoğan (D), Gonca Ay Keselik (D), Mehmet Ali Malas \\ Department of Anatomy, Faculty of Medicine, İzmir Kâtip Çelebi University, İzmir, Turkey
}

\begin{abstract}
In this case report, we present a case with an unusually high course of inferior thyroid artery and its relationship with the recurrent laryngeal nerve on the right side of the neck of a 91 years-old formalin fixed male cadaver. Dissection showed that the inferior thyroid artery gave off branches between the branches of the recurrent laryngeal nerve following a sharp curvature descending downward to the thyroid gland. Knowledge of such a variation of the location and course of the inferior thyroid artery and the recurrent laryngeal nerve is important for surgical and radiological procedures.
\end{abstract}

Keywords: inferior thyroid artery; recurrent laryngeal nerve; thyrocervical trunk; thyroid gland; variation

Anatomy 2021;15(2):171-174 (2021 Turkish Society of Anatomy and Clinical Anatomy (TSACA)

\section{Introduction}

Previous studies discussed the importance of differences in origin, course and distribution of the arteries supplying the thyroid gland and their relationship with the recurrent laryngeal nerve (RLN). ${ }^{[1-4]}$ The variations regarding the course and branching pattern of the arteries of the thyroid gland may also be associated with ethnicity and gender. ${ }^{[3]}$ During the surgical approaches directed to the neck region, it is important to consider the variational relationship between the course of inferior thyroid artery (ITA) and the neighbouring neurovascular structures; particularly, the RLN to prevent iatrogenic injuries. ${ }^{[4,5]}$ In this case report, we report an ITA variant, which has an unusually high course on the right side and its anatomical relations with the RLN.

\section{Case Report}

During routine educational dissection of a 91 years old formalin fixed male cadaver, ITA was observed to have an unexpected long course on the right side of the neck of the cadaver. The artery, after its origin, made a sharp curve inferiorly to reach the thyroid gland (Figures $\mathbf{1 a}$ and $\mathbf{b}$ ). After removing the superficial muscles on the anterior side of the neck region throughout the dissection procedure, the carotid sheath and surrounding structures of the neck were exposed. In order to better visualize the anatomic structures, the anterior thoracic wall was removed and the structures around the subclavian artery were dissected and the branches originating from the subclavian artery were followed. Behind the carotid sheath, ITA, originating from the right thyrocervical trunk, ascended to the level of the fifth cervical vertebra, which can be considered as a very high level. Then it sharply angled down and divided into two branches at the level of the lower half of the thyroid gland. One of these two branches was directed to the lower lobe of the thyroid gland and the other to the upper lobe. One of the two branches of the RLN was ascending anterior to the branches of ITA and the other from the back (Figures 1a and b).

In our case, this course of ITA was present only on the right side. On the left side, ITA divided into branches under the thyroid gland at the level of the sixth cervical vertebra after originating from the thyrocervical trunk. In addition, the course of superior thyroid artery on both sides and their relationship with the external branch of superior laryngeal nerve were regular. The origin, course and branching pattern of superior thyroid arteries on both sides, ITA on the left side and RLN on the left side showed a regular pattern. 


\section{Discussion}

It is known that inferior laryngeal nerve damage is seen at a relatively higher rate after total thyroid resections. ${ }^{[4]}$ In total thyroidectomy, it is important to know the relationships of some structures such as ITA, Berry ligament, Zuckerkandl tubercle and pyramidal lobe formed by the extension of thyroid lobe. Dissection, ligation and excision of these structures according to the technique have remarkable details. ${ }^{[4,5]}$

Inferior laryngeal nerve is composed of mostly motor fibers that enter the larynx. It innervates the laryngeal muscles with different courses on the right and left sides after arising from the vagus nerve. However, its most vulnerable part to the iatrogenic injury is the last part before entering the larynx where it is adjacent to the thyroid gland. This part is just the distal to the intersection of the RLN with ITA. ${ }^{[5,6]}$ In safe thyroidectomy technique, the association of RLN with ITA, Berry ligament, and posterior extension of the growing thyroid lobe is therefore important.$^{[6]}$ In safe thyroidectomy technique, ITA serves as an important landmark for dissection of RLN. Therefore, for preserving the RLN in the surgical dissection of ITA, anatomical variations of ITA should be taken into account. ${ }^{[5]}$

Although several studies about variations of anatomical origin of ITA have been published, ${ }^{[3,7]}$ there are few studies on the course of ITA and its relationship with RLN. RLN is usually located posterior to the ITA on the right side. The relationship between ITA and inferior laryngeal nerve is also very important. ${ }^{[5]}$ Detailed knowledge of neck anatomy contributes effective surgical procedures, as well as help reducing the risk of intraoperative iatrogenic injuries. ${ }^{[8-11]}$ Other causes such as stellate ganglion blocks, central venous catheter placement, ${ }^{[11]}$ and direct trauma may lead to serious injury to ITA. ${ }^{[12]}$ It is reported that using imaging techniques such as ultrasound to identify any variations in anatomical structures prior to surgical and interventional procedures also prevents damage to ITA. ${ }^{[1]}$
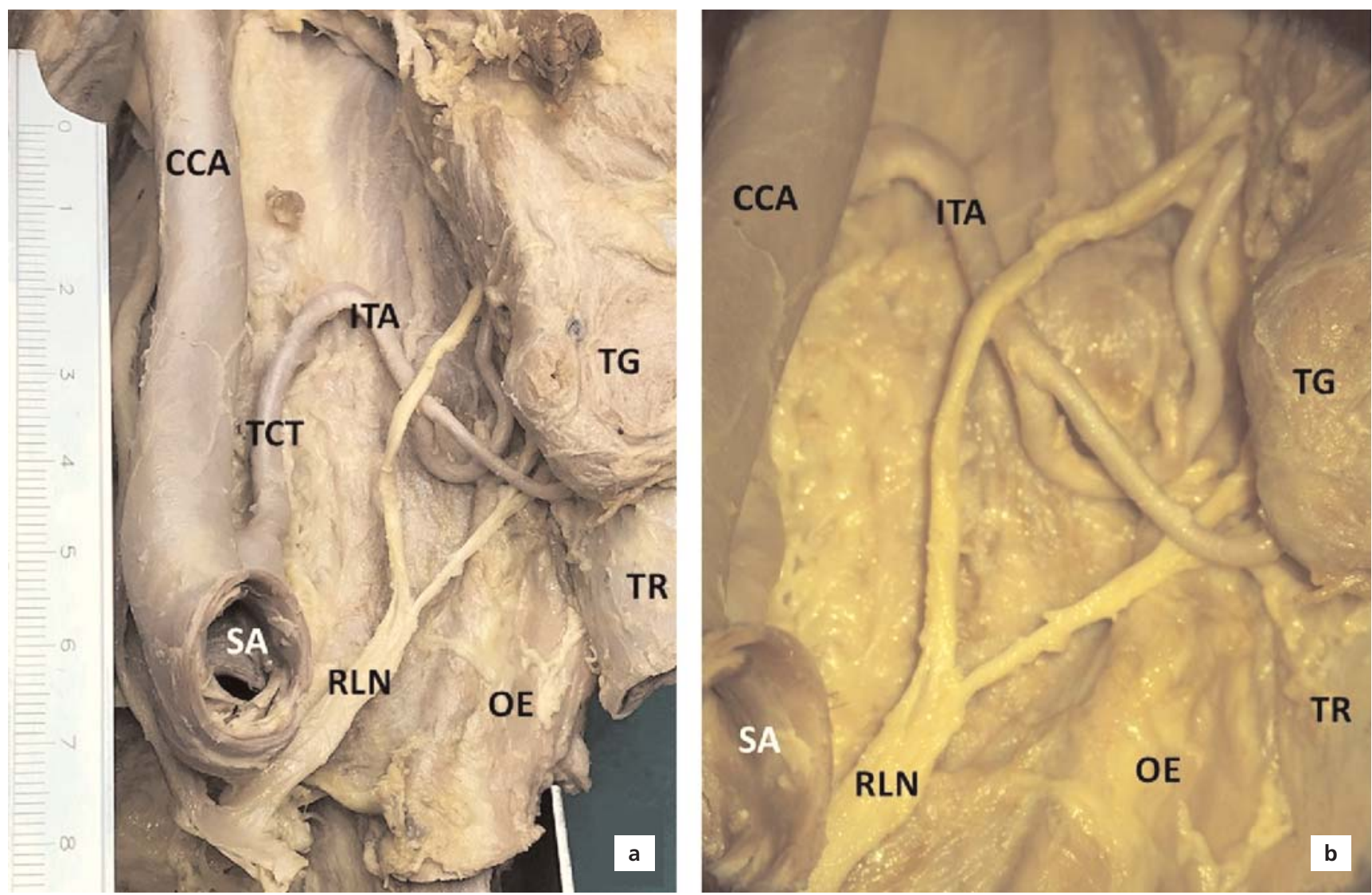

Figure 1. (a) Anterior view of right inferior thyroid artery, right recurrent laryngeal nerve and related structures; (b) magnified view. CCA: common carotid artery; ITA: inferior thyroid artery; OE: oesophagus; RLN: recurrent laryngeal nerve; SA: subclavian artery; TCT: thyrocervical trunk; TG: thyroid gland; TR: trachea. 
Variations of superior thyroid artery and ITA have been previously published by many authors. ${ }^{[1]}$ Sarkar et al. ${ }^{[2]}$ reported an unusually high division level of ITA on the left side. In their report, it is stated that after arising from the thyrocervical trunk, ITA divides into the branches near the upper pole of the thyroid gland while curving inward at the level of the fifth cervical vertebra on the left side. It is reported that the branching of ITA on the left occurs at a higher level than the right side. In our case, it was determined that the ascending ITA suddenly turned downwards with a sharp angle after a long course rising up to the fifth cervical vertebra and ITA was divided into two branches at a level close to the inferior pole of the thyroid gland on the right side.

Makay et al. ${ }^{[6]}$ investigated the relationship between RLN and ITA, and demonstrated sixteen variants of RLN in 253 adult patients. They reported that in most of the cases, RLN is located deep to the ITA. They also reported that RLN divided into 2 branches in $22.5 \%$ and 3 branches in $1.6 \%$ of the cases. They observed nerve bifurcation mostly on the left side. Campos and Henriques ${ }^{[13]}$ dissected 76 formalin fixed cadavers and reported that RLN is mostly located among the branches of ITA in both sexes. In their study, RLN on the right side were found between the branches of ITA in $49.30 \%$, anterior aspect of ITA in $38.04 \%$ and posterior aspect of the ITA in $11.26 \%$ of the cases. However, in our case, the RLN was divided into two branches at the level of subclavian artery on the right side. The inferior branch was ascending underneath the branches of ITA, while the superior branch was ascending superficial to the branches of ITA (Figures 1a and b). Sarkar et al. ${ }^{[2]}$ reported that the left RLN coursed between the branches of ITA at a high level. In our study, on the contrary, on the right side the branches of the ITA passed between the branches of the RLN and gave off the minor branches to the thyroid gland.

Variations of superior thyroid artery, RLN, and ITA should be taken into consideration before and during the surgical procedures directed to the neck and thyroid gland, and are of great importance for the surgeons in order to prevent iatrogenic injuries. Preoperative consideration of arterial variations and their neurovascular relationships may result in better planning of the operation with less iatrogenic neurovascular injury and more favorable results.

\section{Acknowledgments}

The authors sincerely thank those who donated their bodies to science so that anatomical research could be performed. Results from such research can potentially increase mankind's overall knowledge that can then improve patient care. Therefore, these donors and their families deserve our highest gratitude..$^{[14]}$

\section{Conflict of Interest}

The authors have no conflicts of interest to declare.

\section{Author Contributions}

KEÖ: dissection of the case, manuscript writing; KE: manuscript writing; GAK: dissection of the case; MAM: supervision, manuscript editing.

\section{Ethics Approval}

The study was performed following the aid of the ethical standards down in the 1964 Declaration of Helsinki and its later amendments.

\section{Funding}

None.

\section{References}

1. Esen K, Ozgur A, Balci Y, Tok S, Kara E. Variations in the origins of the thyroid arteries on CT angiography. Jpn J Radiol 2018;36:96102 .

2. Sarkar S, Kundu B, Dey S, Saha PK, Meur R, Sadhu A. Variations in the arterial supply of the thyroid gland in an Indian male cadaver. Indian Journal of Basic and Applied Medical Research 2014;3:256-9.

3. Toni R, Della Casa C, Castorina S, Roti E, Ceda G, Valenti G. A meta-analysis of inferior thyroid artery variations in different human ethnic groups and their clinical implications. Ann Anat 2005;187:37185.

4. Tang WJ, Sun SQ, Wang XL, Sun YX, Huang HX. An applied anatomical study on the recurrent laryngeal nerve and inferior thyroid artery. Surg Radiol Anat 2012;34:325-32.

5. Henry BM, Vikse J, Graves MJ, Sanna S, Sanna B, Tomaszewska IM, Hsieh WC, Tubbs RS, Tomaszewski KA. Variable relationship of the recurrent laryngeal nerve to the inferior thyroid artery:a metaanalysis and surgical implications. Head Neck 2017;39:177-86.

6. Makay O, Icoz G, Yilmaz M, Akyildiz M, Yetkin E. The recurrent laryngeal nerve and the inferior thyroid artery: anatomical variations during surgery. Langenbecks Arch Surg 2008;393:681-5.

7. Graves M, Henry B, Sanna B, Pękala P, Taterra D, Witczak K, Kucharska E, Barczyński M, Walocha J, Tomaszewski K. Anatomical variations of the inferior thyroid artery: a cadaveric examination. Przeglàd Lekarski 2017;74:633-5.

8. Aziz F, Lehman EB, Reed AB. Increased duration of operating time for carotid endarterectomy is associated with increased mortality. Ann Vasc Surg 2016;36:166-74.

9. Kuhn JE, Lebus V GF, Bible JE. Thoracic outlet syndrome. J Am Acad Orthop Surg 2015;23:222-32.

10. Moreau S, Goullet de Rugy M, Babin E, Salame E, Delmas P, Valdazo A. The recurrent laryngeal nerve: related vascular anatomy. Laryngoscope 1998;108:1351-3.

11. Ghai A, Kaushik T, Wadhera R, Wadhera S. Stellate ganglion blockade-techniques and modalities. Acta Anaesthesiol Belg 2016;67:1-5. 
12. Petrocheilou G, Myrianthefs P, Evodia E, Vlychou M, Kokkinis CE. Inferior thyroid artery pseudoaneurysm caused by blunt trauma. Vascular 2010;18:242-5.

13. Campos BA, Henriques PR. Relationship between the recurrent laryngeal nerve and the inferior thyroid artery: a study in corpses. Rev Hosp Clin Fac Med Sao Paulo 2000;55:195-200.

ORCID ID:

K. E. Özen 0000-0002-9778-3325; K. Erdoğan 0000-0003-0417-4094; G. Ay Keselik 0000-0001-5469-1714; M. A. Malas 0000-0002-1451-0672
14. Iwanaga J, Singh V, Ohtsuka A, Hwang Y, Kim HJ, Moryś J, Ravi KS, Ribatti D, Trainor PA, Sañudo JR, Apaydin N, Şengül G, Albertine KH, Walocha JA, Loukas M, Duparc F, Paulsen F, Del Sol M, Adds P, Hegazy A, Tubbs RS. Acknowledging the use of human cadaveric tissues in research papers: recommendations from anatomical journal editors. Clin Anat 2020;34:2-4.

Correspondence to: Kemal Emre Özen, MD, PhD Department of Anatomy, Faculty of Medicine, Izmir Kâtip Çelebi University, Izmir, Turkey Phone: +902323293535/5811 e-mail: kemalemre9870@yahoo.com Conflict of interest statement: No conflicts declared.

This is an open access article distributed under the terms of the Creative Commons Attribution-NonCommercial-NoDerivs 4.0 Unported (CC BY-NCND4.0) Licence (http://creativecommons.org/licenses/by-nc-nd/4.0/) which permits unrestricted noncommercial use, distribution, and reproduction in any medium, provided the original work is properly cited. How to cite this article: Özen KE, Erdoğan K, Ay Keselik G, Malas MA. The anatomical relationship between recurrent laryngeal nerve and high inferior thyroid artery: a case report. Anatomy 2021;15(2):171-174. 